Dr MILAN RADOVANOVIĆ

Kraljevo, Vojvode Putnika 15/15

mradowanovic@gmail.com

UDK 314.151.3-054.7(=411.16)(569.4)"1948/1952"

originalan naučni rad

primljeno: 14. septembar 2015

929.52БЕШИНСКИ"1948"

341.7(497.1:410)"1946/1947"

prihvaćeno: 4. novembar 2015.

\title{
DER TRANSIT JÜDISCHER MIGRANTEN DURCH JUGOSLAWIEN NACH PALÄSTINA UND ISRAEL (1933-1952) DER FALL ERNEST UND ILSA ESCHINSKY
}

ZUSAMMENFASSUNG: In diesem Aufsatz wird die Verbindung zwishen dem Zustrom jüdischer Flüchtlinge der Zwischenkriegszeit und der organisierten Auswanderung aus Jugoslawien nach Israel, die zwischen 1948 und 1952 angesprochen. Lediglich einzelne Juden hatten es geschafft, Zuflucht vor dem nazistischen Regime in Jugoslawien zu finden und, nachdem sie den Krieg überlebt hatten, an der organisierten Auswanderung nach Israel teilzunehmen. Daher ermöglicht erst die Dekonstruktion des kompletten Migrationsprozesses bis auf die Ebene einzelner Teilnehmer einen Einblick in die existierende Kontinuität.

SCHLÜSSELWÖRTER: Migration, Jugoslawien, Palästina, Israel, Juden, Ernest Beschinsky, Ilsa Beschinsky

\section{Einleitung}

Die Migrationsströme jüdischer Bevölkerung in Richtung Palästina und später Israel, die Jugoslawien erreichten, können in drei Phasen gegliedert werden. In der Zwischenkriegszeit diente das Königreich als Transitbereich für jüdische Flüchtlinge aus dem Dritten Reich, bzw. den Gebieten, die Deutschland annektiert oder besetzt hatte. Obwohl nur ein relativ kleiner Anteil dessen Gesamtzahl, hatten es einige dieser Flüchtlinge auf das britische Mandatsgebiet in Palästina abgesehen. ${ }^{1}$ Der gleiche Migrationsprozess

${ }^{1}$ Mehr dazu: Milan Ristović, „Turisti pod sumnjom (o jednom vidu politike Kraljevine Jugoslavije prema jevrejskim izbeglicama 1938-1941 godine)“, Zbornik radova sa okruglog stola Kladovo transport, priredila Milica Mihailović (Beograd: Jevrejski istorijski muzej, Savez jevrejskih opština Srbije, 2006), 170-189 (weiter: M. Ristović, „Turisti pod sumnjom“...); Milan Ristović, „Jugoslavija i jevrejske izbeglice 1938-1941“, Istorija 20. veka, br. 1 (1996), 21-43 (weiter: M. Ristović, „Jugoslavija“...); Milan Ristović, „Unsere und fremde 
wurde einigermaßen nach dem Krieg erneuert, als das sozialistische Jugoslawien einige der kleineren Häfen am Adriatischen Meer für den Transit ehemaliger KZ-Häftlinge in Richtung Palästina freigab. ${ }^{2}$ Dir Gründung eines unabhängigen israelischen Staates im Mai 1948 führte dazu, dass die Immigration jüdischer Bevölkerung einen massenhaften Charakter annahm. An dieser haben sich endlich auch jugoslawische Juden ohne bedeutendere Einschränkungen beteiligen können. ${ }^{3}$

Antisemitismus war, obwohl in unterschiedlichen Formen und von diverser Intensität, zum Leitmotiv der europäischen politischen Szene in der Zwischenkriegszeit geworden. ${ }^{4}$ Von der alltäglichen Verfolgung flüchtend, versuchte der Großteil der europäischen Juden es in die Vereinigten Staaten von Amerika oder aber ins britische Mandatsgebiet in Palästina zu schaffen. Der Transit durch das Balkangebiet gewann zunehmend an Bedeutung dank der immer restriktiver werdenden Migrationspolitik Großbritanniens und der Vereinigten Staaten. Jugoslawiens spezifische geografische Lage führte dazu, dass es nach 1933 zu einer der bedeutendsten Zwischenstationen für nahezu 50.000 jüdische Flüchtlinge wurde. ${ }^{5}$ Am Ende des Zweiten Weltkrieges wurde der jugoslawische Staat auf alternativen politischen und ideologischen Grundlagen wieder aufgebaut. Der Umstand, die außenpolitischen Ziele der Sowjetunion zu berücksichtigen, ${ }^{6}$ führte aber erneut dazu, dass Jugoslawien die Rolle des Transitgebietes für jüdische

Juden. Zum Problem der Jüdischen Flüchtlinge in Jugoslawien 1938-1941“, in: Dahlmann, Dittmar, Hilbrenner, Anke (Ed.), Zwischen grossen Erwartungen und bösem Erwachen. Juden, Politik und Antisemitismus in Ost- und Südosteuropa 1918-1945, (Paderborn, Ferdinand Schöningh Verlag, 2007), 191-216. (weiter: M. Ristović, „Unsere und fremde Juden“...); Anna Grünfelder, „Aufgeschobene Vernichtung. Jüdische Emigration nach Jugoslawien (1933-1938-1945)“, Südosteuropafor-schung 71 (2012), 233-284. (weiter: Grünfelder, „Aufgeschobene Vernichtung“...).

${ }^{2}$ Siehe hierzu: Mladenka Ivanković, „Odlazak jevrejskih izbeglica-žrtava Holokausta iz evropskih zemalja za Palestinu preko teritorije Jugoslavije 1946/7. godine“, Tokovi istorije 3 (2006), 141-153. (weiter: Ivanković, Mladenka, „Odlazak jevrejskih izbeglica... “)

${ }^{3}$ Zur organisierten Auswanderung jugoslawischer Juden nach Israel, siehe: Mladenka Ivanković, Jevreji u Jugoslaviji 1944-1952 (Beograd: INIS, 2009), 315-354. (weiter: Ivanković, Jevreji u Jugoslaviji (1944-1952)...); Zu Einzelnaspekten des gleichen Prozesses: Милан Радовановић, „Исељење јеврејске деце из Југославије у Израел 1948/9“, Наша $\bar{u}$ рошлосӣ, 14, (2013), 161-170; Милан Радовановић, „Поједини економски аспекти организованог исељавања југословенских Јевреја у Израел 1948/9. године“, Гоguшњак за gрушишвену истиорију, 3, (2011), 81-102; Милан Радовановић, „The Sound of Silence Југословенска штампа о организованом исељавању Јевреја из Југославије у Израел (1948-1952)“, Годишњак за руштивену истиорију, 1, (2013), 77-91.

${ }^{4}$ M. Ristović, „Jugoslavija...", 21-23.

${ }^{5}$ Harriet Pass Freidenreich, The Jews of Yugoslavia (Philadelphia: Jewish Publication Society of America, 1979), 180.

${ }^{6}$ Od Arne Vestad, Globalni Hladni rat (Beograd: Arhipelag, 2008), 171. 
Flüchtlinge, die in Richtung des britischen Mandatsgebietes im Nahen Osten migrierten, zu spielen hatte. Die jugoslawische Regierung hat, in $\mathrm{Zu}-$ sammenarbeit mit diversen internationalen jüdischen Organisationen, im Laufe des Jahres 1946 die ersten illegalen Transporte nach Palästina zustande gebracht. ${ }^{7}$

Die Gründung eines souveränen Staates Israel führte dazu, dass sämtliche Einschränkungen der Einwanderungsrechte von Juden, die im britischen Palästina in Kraft waren, nichtig wurden. Es folgte eine der größten und bedeutendsten Migrationsbewegungen des XX Jahrhunderts. Zwischen 1949 und 1951 siedelten sich nahezu 700.000 Juden aus allen Teilen der Welt in Israel an. ${ }^{8}$ Im gleichen Zeitraum verließen in fünf Wellen der organisierten Auswanderung 7.739 Juden Jugoslawien mit der Absicht, sich im neu gegründeten nationalen Staat im Nahosten niederzulassen. ${ }^{9}$

Die erste Welle jugoslawischer Juden hat sich im Dezember 1948 und Januar 1949 nach Israel begeben. ${ }^{10}$ Die nächste organisierte Auswanderung erfolgte im Juni bzw. Juli 1949. ${ }^{11}$ Im März 1950 haben die jugoslawischen Juden der dritten organisierten Auswanderungswelle den Hafen in Rijeka verlassen. ${ }^{12}$ Die Migration lief Ende Mai 1951 weiter. ${ }^{13}$ Die letzte organisierte Auswanderung jugoslawischer Juden nach Israel fand im Oktober 1952 statt. $^{14}$

${ }^{7}$ Laut Mladenka Ivanković, haben im Jahr 1946 insgesammt 7.294 Juden über jugoslawische Häfen ihren Weg nach Palästina gefunden, Ivanković, Jevreji u Jugoslaviji (1944-1952)..., 301.

${ }^{8}$ Itzhak Alfassi, Immigration and Settlement (Jerusalem: Keter Books, 1973), 56. Siehe dazu auch: Shoshanna Neumann, Aliyah to Israel: Immigration under Conditions of Adversity (Bonn: IZA, 1999), 1-5.

${ }^{9}$ Marko Perić, Srećko Stanić, „Jevreji Beograda u popisima stanovništva XIX i XX veka“, Zbornik Jevrejskog istorijskog muzeja, 6, (1992), 295.

${ }^{10}$ Archiv des Jüdischen Historischen Museums (Arhiv Jevrejskog istorijskog muzeja - weiter AJIM), Box (B.) 827, Dopis Saveza jevrejskih veroispovednih opština Jugoslavije (SJVOJ), svim jevrejskim veroispovednim opštinama Jugoslavije, Predmet: Izveštaj o odlasku u državu Izrael, 17. I 1949, Pov. br. 94/49.

${ }^{11}$ AJIM, B. 827, Dopis SJVOJ, svim jevrejskim veroispovednim opštinama Jugoslavije (Cirkular br. XXXII), Predmet: Izveštaj o završetku drugog iseljenja u državu Izrael, 2. VIII 1949.

12 AJIM, B. 871, Zapisnik zajedničke sednice Izvršnog odbora i Autonomnog odbora SJVOJ, 18. IV 1950.

13 AJIM, B. 743, Dopis SJVOJ, Glavnoj direkciji železnica, Upravi saobraćajnotransportne službe u Beogradu, Predmet: Transportovanje iseljenika Jevreja iz Jugoslavije u Rijeku - Izrael, 11. V 1951.

${ }^{14}$ Siehe dazu: AJIM, B. 754, V grupno iseljenje, 19. IX 1952. und AJIM, B. 754, Dopis SJVOJ, svim jevrejskim veroispovednim opštinama Jugoslavije, Predmet: Peto grupno iseljenje u državu Izrael (Cirkular br. VII), 18. IX 1952, Pov. br. 1798/52. 
Obwohl es sich zweifellos um zwei Phasen im gleichen Migrationsprozess handelt, ist eine Kontinuität zwischen dem Zustrom von jüdischen Flüchtlingen ins Königreich Jugoslawien und der organisierten Auswanderung, aufgrund der uns zur Verfügung stehenden Dokumente, sehr schwer nachzuweisen. Der Großteil der Juden, die Jugoslawien am Vorabend des Krieges erreicht hatten, hat das Land vor dem deutschen Angriff auf das Königreich verlassen, oder ist bei der Umsetzung der „Endlösung“ in den besetzten Gebieten ums Leben gekommen. ${ }^{15}$

Aus dem Grund hat die organisierte Auswanderung der Nachkriegszeit nur begrenzt an den Zustrom von Flüchtlingen aus dem Dritten Reich und anderen Gebieten, die unter direktem Druck Deutschlands litten, anknüpfen können. Es waren lediglich einzelne Juden, die es geschafft hatten, Zuflucht vor dem nazistischen Regime in Jugoslawien zu finden und die, nachdem sie den Krieg überlebt hatten, an der organisierten Auswanderung nach Israel teilnahmen.

Erst die Dekonstruktion des kompletten Migrationsprozesses bis auf die Ebene einzelner Teilnehmer ermöglicht einen Einblick in die existierende Verbindung zwischen dem Zustrom jüdischer Flüchtlinge und der Massenauswanderung jugoslawischer Juden nach Israel. ${ }^{16}$ Die Individualisierung der Migrationsbewegungen, die Juden durch Jugoslawien nach $\mathrm{Pa}-$ lästina und später Israel geführt haben, umgeht aber nur teilweise das Problem mangelnder Dokumente.

$\mathrm{Zu}$ einzelnen Juden, die es auf illegalem Wege geschafft haben, das Königreich Jugoslawien zu erreichen, stehen uns nur wenige relevante Informationen zur Verfügung. Individuelle Flüchtlinge blieben im Rahmen des Prozesses mehr oder weniger „unsichtbar“. ${ }^{17}$ Umso komplizierter ist es, diese nur wenigen Auswanderer innerhalb der organisierten Emigration jugoslawischer Juden nach Israel weiter zu verfolgen.

Nur ein Prozent der Auswanderer, die Jugoslawien zwischen 1948 und 1952 verließen waren ausländische Juden. ${ }^{18}$ Diese konnten sich unter gleichen Umständen wie auch jugoslawische Juden nach Israel begeben,

${ }^{15}$ Grünfelder, Aufgeschobene Vernichtung..., 250.

${ }^{16}$ Milan Radovanović, „The State, the Organization and the Individual - A threelevel Approach to Migration“, in: Where is Civil Society in Central Europe heading to?, Košice 2015, 169-187.

${ }^{17}$ Detallierte Daten stehen uns, nur zu denjenigen Flüchtlingen zur Verfügung, deren Antrag auf ein Transitvisum nicht genehmigt wurde. Eine große Anzahl solcher Anträge kann im Bestand des Königlichen Generalkonsulats Jugoslawiens in Hamburg gefunden werden. Dieser wird im Archiv Jugoslawiens aufgehoben, Archiv Jugoslawiens (Arhiv Jugoslavije), Bestand 421, Box 2, Ordner 12.

${ }^{18}$ M. Ivanković, Jevreji u Jugoslaviji (1944-1952)..., 318. 
wobei sie ihren Anträgen auf Auswanderung einen gültigen Reisepass und schriftliche Erlaubnis ihres Heimatstaates beiliegen mussten. ${ }^{19}$ Jüdische Flüchtlinge, die in der Zwischenkriegszeit Jugoslawien erreicht hatten, waren den gleichen Regeln unterlegen. Insofern stellt auch lediglich deren Identifizierung innerhalb der organisierten Auswanderung eine Herausforderung dar. In den vorhandenen Dokumente findet sich mit Sicherheit nur ein Brautpaar, das Jugoslawien in der Zwischenkriegszeit, auf der Flucht vor dem nationalsozialistischen Regime erreicht hat. Dieser Einzelfall muss aber ausschließlich als Fallstudie betrachtet werden, da er aufgrund mangelnder Dokumente, nicht als repräsentativ für die organisierte Auswanderung im Allgemeinen angesehen werden kann.

\section{Ernest und Ilsa Beschinsky}

Mit den Flüchtlingen, die das Königreich Jugoslawien nach dem "Anschluss“ Österreichs erreicht haben ${ }^{20}$ kamen auch Ernest und Ilsa Beschinsky nach Zagreb. Sie erreichten Jugoslawien, nachdem sie sich kurz in der Tschechoslowakei aufgehalten hatten. ${ }^{21}$ Beschinsky war Beamter, vom Vater Ignjat und Mutter Judite im Jahre 1902 in Wien geboren. ${ }^{22}$ Ilsa, geb. Focke, geboren 1909 in Salzburg, war Hausfrau.

Die uns zur Verfügung stehenden Dokumente sagen wenig über das Kriegsschicksal des Brautpaares Beschinsky aus. Mit Sicherheit kann man nur behaupten, dass Ilsa, die Nicht-Judin war, eine Wohnung in Zagreb gemietet hatte, wo sie und ihr Mann bis Ende des Krieges Zuflucht gefunden haben. ${ }^{23}$ Das nächste Mal tauchen Ernest und Ilsa Beschinsky in den Quellen als Applikanten für die erste Welle der organisierten Auswanderung aus Jugoslawien nach Israel auf. Ihr Versuch, innerhalb der ersten

${ }^{19}$ Siehe dazu: AJIM, B. 755, Dopis SJVOJ, svim jevrejskim veroispovednim opštinama Jugoslavije, Predmet: Odlazak u državu Izrael, 26. VIII 1948, Pov. br. 1216/48; AJIM, B. 827, Dopis SJVOJ, svim jevrejskim veroispovednim opštinama Jugoslavije, Predmet: Drugo iseljenje u državu Izrael, 19. II 1949, Pov. br. 342/49; AJIM, B. 1288, Dopis SJVOJ, svim jevrejskim veroispovednim opštinama Jugoslavije (Cirkular br. I), Predmet: Treće iseljenje u državu Izrael, 23. X 1949, Pov. br. 3481/49; AJIM, B. 827, Dopis svim jevrejskim veroispovednim opštinama Jugoslavije (Cirkular br. I), Predmet: Četvrto iseljenje u državu Izrael; AJIM, B. 855, Dopis SJVOJ, svim jevrejskim veroispovednim opštinama Jugoslavije (Cirkular br. I), Predmet: Peto grupno iseljenje u državu Izrael, 12. IV 1952, Pov. br. 604/52.

${ }^{20}$ AJIM, B. 758, An den Bund der jüdischen Gemeinden in Beograd, z.H. Herrn Präsident Dr. Alkalaj, Beograd, 71. ulica 7. jula, Betr: Ernest Beschinsky (Bešinski), geb. 12. 7. 1902, in Wien, aus Zagreb, Nemšićeva 6, derzeit in der Strafanstalt Stara Gradiška, III odjel, soba 17, Auswanderung nach Israel, 8. III 1949, Pov. br. 540/49.

21 AJIM, B. 758, Molba Ernesta Bešinskog (1902), iz Zagreba, sada na izdržavanju kazne u KPD Stara Gradiška, III odeljenje, soba br. 17, radi iseljenja u državu Izrael.

${ }^{22}$ AJIM, B. 856, Prijava za iseljenje Ernesta Bešinskog, 16. XI 1948.

${ }^{23}$ Siehe Fußnote Nr. 21. 
Welle der organisierten Auswanderung das Land zu verlassen, scheiterte jedoch.

Anfang Mai 1948, als die Vorbereitungen für die erste Welle der organisierten Auswanderung jugoslawischer Juden nach Israel immer noch nicht angefangen hatten, wurden Ernest und Ilsa Beschinsky verhaftet und unter Anklage, eine Strafftat gegen Volk und Staat begangen zu haben, vor Gericht gestellt. ${ }^{24}$ Angeblich hatte das Brautpaar während des Krieges einer Spionin Namens Hermann, deren Ehemann nach dem Kriegsende als Angehöriger der Gestapo verhaftet wurde, Unterkunft gewährt. ${ }^{25}$ Die beiden wurden auch mehrerer Verletzungen der Zoll- und Geldhandelsgesetzte des sozialistischen Jugoslawiens beschuldigt. Das Amtsgericht in Zagreb hatte Ernest Beschinsky ursprünglich zu einer 18 Monate langen Inhaftierung verurteilt, doch wurde diese Entscheidung vom Obersten Gerichtshof der Volksrepublik Kroatien in zweieinhalbjährige Zwangsarbeit umgewandelt. ${ }^{26}$ Beschinsky hätte auch noch nach Ablauf der Strafe aus Jugoslawien vertrieben werden sollen. Seine Frau wurde zu einer Haftstrafe von 6 Monaten veurteilt.

Nachdem ihre Strafe abgelaufen war, wendete sich Ilsa Beschinsky Mitte November 1948 an die Jüdische Glaubensgemeinde in Zagreb, in der Hoffnung, dass ihr Mann und sie sich nachträglich der ersten organisierten Auswanderung anschließen könnten. ${ }^{27}$ Ernest Beschinsky hatte zwischenzeitig deswegen einen schriftlichen Antrag auf Begnadigung gestellt. Dies war ein Bestandteil der Standardbewerbungsprozedur für Häftlinge und Sträflinge, die sich der organisierten Auswanderung nach Israel anschließen wollten. ${ }^{28}$ Beschinsky richtete seinen Antrag zuerst an das Innenministerium (Ministarstvo unutrašnjih poslova Jugoslavije), ${ }^{29}$ schrieb aber danach auch das Präsidium der Volksversammlung (Prezidijum Narodne

24 AJIM, B. 856, Molba Bešinski Ernesta, Prezidijumu Narodne skupštine FNRJ, u Beogradu, 16. XI 1948.

${ }^{25}$ AJIM, B. 758, Presuda, 21. IX 1948.

${ }^{26}$ Siehe Fußnote Nr. 20.

${ }^{27}$ AJIM, B. 856, Dopis JVO Zagreb, SJVOJ-u, 16. XI 1948, 16. XI 1948, Pov. br. $2235 / 48$.

${ }^{28}$ Siehe dazu: AJIM, B. 768, Dopis SJVOJ, svim jevrejskim veroispovednim opštinama Jugoslavije, Predmet: Odlazak u Izrael, 2. XI 1948, Pov. br. 1857/48; AJIM, B. 827, Dopis SJVOJ, svim jevrejskim veroispovednim opštinama Jugoslavije, Predmet: Drugo iseljenje u državu Izrael, 19. II 1949, Pov. br. 342/49; AJIM, B. 1288, Dopis SJVOJ, svim jevrejskim veroispovednim opštinama Jugoslavije (Cirkular br. I), Predmet: Treće iseljenje u državu Izrael, 23. X 1949, Pov. br. 3481/49; AJIM, B. 827, Dopis svim jevrejskim veroispovednim opštinama Jugoslavije (Cirkular br. I), Predmet: Četvrto iseljenje u državu Izrael; AJIM, B. 855, Dopis SJVOJ, svim jevrejskim veroispovednim opštinama Jugoslavije (Cirkular br. I), Predmet: Peto grupno iseljenje u državu Izrael, 12. IV 1952, Pov. br. 604/52.

${ }^{29}$ AJIM, B. 755, Molba Ernsta Bešinskog, MUP FNRJ, 17. IX 1948. 
skupštine FNRJ) an. ${ }^{30}$ Da sich das Brautpaar Beschinsky mit Verspätung für die erste organisierte Auswanderung beworben hatte, wurden alle mit dieser Bewerbung verbundene Anträge als nichtig betrachtet.

Obwohl Bewerbungsfristen für einzelne Wellen immer als endgültig bezeichnet wurden, haben sowohl lokale Gemeinden als auch der Bund jüdischer Glaubensgemeinden Jugoslawiens (BjGJ) immer wieder drauf bestanden, dass auch nachträglich auf Auswanderung gestellte Anträge angenommen werden. Obwohl die Frist dafür am 31. Oktober 1948 abgelaufen war, ${ }^{31}$ insistierte die Leitung der Gemeinde in Zagreb, dass die Bewerbung des Brautpaares Beschinsky für die erste Welle der organisierten Auswanderung nachträglich akzeptiert werde. ${ }^{32}$ Diesen Antrag haben jedoch sowohl die zuständigen staatlichen Einrichtungen als auch der BjGJ abgelehnt.

Nachdem ihre und die Bewerbung ihres Mannes für die organisierte Auswanderung nach Israel Ende 1948 fehlgeschlagen war, zog Ilsa Beschinsky zurück nach Österreich. ${ }^{33}$ Nachdem sie sich in Wien vorübergehend niedergelassen hatte, engagierte sie sich erneut für die Auswanderung nach Israel. Bei der jüdischen Glaubensgemeinde Zagreb gab sie eine Bewerbung für die zweite Welle der organisierten Emigration. Diese bezog sich auch auf Ernest Beschinsky, der immer noch inhaftiert war. ${ }^{34}$ Seiner Bewerbung wurde erneut ein entsprechender Antrag auf Begnadigung beigefügt. ${ }^{35}$

Die uns zur Verfügung stehenden Dokumente weisen keinerlei relevante Daten über das Brautpaar Beschinsky nach Mitte des Jahres 1949 auf. Es steht jedoch fest, dass sie Jugoslawien im Rahmen der weiteren organisierten Auswanderungswellen, die bis 1952 stattfanden, nicht verlassen haben. ${ }^{36}$ Wie es scheint, haben sich Ernest und Ilsa Beschinsky für die Auswanderung nach 1949 nicht einmal mehr beworben. Parallel zur Massenauswanderung entwickelte sich aber auch ein Prozess der individuellen Emigration. So kann man die Möglichkeit nicht ausschließen, dass das Brautpaar Beschinsky sich aus Jugoslawien doch noch nach Israel begeben hat.

${ }^{30}$ Siehe Fußnote Nr. 24.

${ }^{31}$ AJIM, B. 827, Dopis SJVOJ, svim jevrejskim veroispovednim opštinama Jugoslavije, 25. X 1948, Pov. br. 1756/48.

${ }^{32}$ Siehe Fußnote Nr. 25. br. 540/49.

${ }^{33}$ AJIM, B. 756, Dopis SJVOJ, Ilzi Bešinski iz Solbad Hala u Tirolu, 2. IV 1949, Pov.

${ }^{34}$ AJIM, B. 758, Dopis SJVOJ, JVO Zagreb, 2. IV 1949.

${ }^{35}$ Siehe Fußnote Nr. 21

${ }^{36}$ AJIM, B. 1288, Spisak iseljenika za Izrael, VI-VII 1949; AJIM, B. 1288, Spisak (III alija); AJIM, B. 801, Četvrto grupno iseljenje u državu Izrael, maja 1951; AJIM, B. 801, Spisak prijavljenih lica za peto grupno iseljenje, jul 1952. 


\section{Schlussfolgerungen}

Während Jugoslawien in der ersten der hier identifizierten Phasen der jüdischen Immigration nach Palästina Rolle als Transitland spielte, fungierte es als Ausgangsort für die organisierte Auswanderung nach Israel. Die minimalen Ausmaße der Verbindung zwischen diesen zwei Phasen machen aber den Nachwein einer Kontinuität entsprechend kompliziert. Ein zusätzliches Problem stellt dabei die Quellenlage dar. Der Mangel an Dokumenten die über die Umstände, unter welchen ausländische Juden Jugoslawien erreicht haben, Auskunft geben, macht es fast unmöglich, Flüchtlinge aus der Zwischenkriegszeit von anderen Ausländern innerhalb der organisierten Auswanderung zu unterscheiden. Der Fall der Ernest und Ilsa Beschinsky ist in dem Sinne einzigartig.

Das Beispiel des Brautpaares Beschinsky, der einzigen Migranten deren Schicksal von der illegalen Einwanderung der Zwischenkriegszeit bis zu den Versuchen, sich innerhalb der organisierten Auswanderung nach Israel zu begeben, nachverfolgt werden kann, kann keineswegs als typisch oder repräsentativ gelten. Solch eine Extrapolation wäre, aufgrund mangelnder Dokumente und der Besonderheit des betrachteten Beispiels, nicht zu rechtfertigen. Das einzige, das der Fall von Ernest und Ilsa Beschinsky zweifellos zeigt, ist, dass sich innerhalb der organisierten Auswanderung sicherlich auch eine kleine Gruppe an Flüchtlingen befand, die bereits in der Zwischenkriegszeit Jugoslawien erreicht hatte und schließlich nach dem Krieg nach Israel aufbrechen durfte.

\section{QUELLEN UND LITERATURVERZEICHNIS}

Archiv des Jüdischen Historischen Museums (Arhiv Jevrejskog istorijskog muzeja) AJIM.

Archiv Jugoslawiens (Arhiv Jugoslavije), (AJ), Bestand (fond) 421, Generalni konzulat Kraljevine Jugoslavije u Hamburgu. 1973.

Alfassi, Itzhak. Immigration and Settlement. Jerusalem: Keter Books,

Grünfelder, Anna. „Aufgeschobene Vernichtung. Jüdische Emigration nach Jugoslawien (1933-1938-1945)“. Südosteuropaforschung 71 (2012), 233-284.

Ivanković, Mladenka. „Odlazak jevrejskih izbeglica - žrtava Holokausta iz evropskih zemalja za Palestinu preko teritorije Jugoslavije 1946/7. godine". Tokovi istorije 3 (2006), 141-153.

Ivanković, Mladenka. Jevreji u Jugoslaviji 1944-1952. Beograd: INIS, 2009. 
Neumann, Shoshanna. Aliyah to Israel: Immigration under Conditions of Adversity. Bonn: IZA, 1999.

Радовановић, Милан. „Поједини економски аспекти организованог исељавања југословенских Јевреја у Израел 1948/9. године“. Гоguшюак за ярушишвену исиоорију, 3, (2011), 81-102.

Радовановић, Милан. „Исељење јеврејске деце из Југославије у

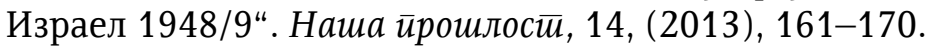

Радовановић, Милан. „The Sound of Silence - Југословенска штампа о организованом исељавању Јевреја из Југославије у Израел (1948-1952)“. Го иишьак за gрушишвену истиорију, 1, (2013), 77-91.

Radovanović, Milan. „The State, the Organization and the Individual - A three-level Approach to Migration". In: Where is Civil Society in Central Europe heading to?, 169-187. Košice, 2015.

Ristović, Milan. „Jugoslavija i jevrejske izbeglice 1938-1941“. Istorija 20. veka. br. 1, (1996), 21-43.

Ristović, Milan. „Turisti pod sumnjom (o jednom vidu politike Kraljevine Jugoslavije prema jevrejskim izbeglicama 1938-1941. godine)“. Zbornik radova sa okruglog stola Kladovo transport. Priredila Milica Mihailović, 170-189. Beograd: Jevrejski istorijski muzej, Savez jevrejskih opština Srbije, 2006.

Ristović, Milan. „Unsere und fremde Juden. Zum Problem der Jüdischen Flüchtlinge in Jugoslawien 1938-1941“. In: Dahlmann, Dittmar, Hilbrenner, Anke (Ed.), Zwischen grossen Erwartungen und bösem Erwachen. Juden, Politik und Antisemitismus in Ost- und Südosteuropa 1918-1945, 191216. Paderborn, Ferdinand Schöningh Verlag, 2007).

Pass Freidenreich, Harriet. The Jews of Yugoslavia. Philadelphia: Jewish Publication Society of America, 1979.

Perić, Marko, Srećko Stanić. „Jevreji Beograda u popisima stanovništva XIX i XX veka“. Zbornik Jevrejskog istorijskog muzeja, 6, (1992), 277-309.

Vestad, Od Arne. Globalni Hladni rat. Beograd: Arhipelag, 2008.

Milan Radovanović

\section{MIGRACIJE JEVREJSKOG STANOVNIŠTVA U PALESTINU I IZRAEL (1933-1955) PREKO TERITORIJE JUGOSLOVENSKE DRŽAVE - SLUČAJ ERNESTA I ILZE BEŠINSKI}

\section{Rezime}

Članak se bavi kontinuitetom između ilegalnog priliva jevrejskih izbeglica u Kraljevinu Jugoslaviju i organizovanog iseljavanja jugoslovenskih Jevreja u Izrael između 1948. i 1952. godine. Kako bi se ukazalo na 
konkretnu vezu između dve faze učešća jugoslovenske države u migracijama u smeru Palestine, odnosno novostvorene jevrejske države, dva procesa su svedena na nivo ličnih istorija pojedinačnih učesnika. Razmatran je primer Ernesta i Ilze Bešinski, jedinih iseljenika čije se kretanje u kontinuitetu može pratiti od dolaska u Kraljevinu, posle „anšlusa“ do podnošenja prijave za priključenje organizovanoj emigraciji. Rad je napisan na osnovu građe koja se čuva u Arhivu Jevrejskog istorijskog muzeja u Beogradu.

KLJUČNE REČI: migracije, Jugoslavija, Palestina, Izrael, Jevreji, Ernest Bešinski, Ilza Bešinski

\section{THE TRANSIT OF JEWISH MIGRANTS THROUGH YUGOSLAVIA EN ROUTE TO PALESTINE AND ISRAEL (1933-1952) - THE CASE OF ERNEST AND ILSA BESCHINSKY}

\section{Summary}

This paper deals with the continuity between the illegal influx of Jewish refugees into the Kingdom of Yugoslavia and the organized emigration of Yugoslav Jews to Israel, which took place between 1948 and 1952. For it to be possible to directly point out the connection between two separate stages of Yugoslav state participation in the migration process, the interwar-period migration to Palestine and the mass migration movement of the post-war period were deconstructed to the level of individuals taking part in it. The case of Ernest and Ilsa Beschinsky was examined, as they are the only refugees whose movement can be traced in relative detail from the moment of arrival in the Kingdom of Yugoslavia, consequent to the "Anschluss" of Austria to the time of applying for the organized emigration to Israel. The paper is based on documents held in the Archives of the Jewish historical museum in Belgrade.

KEYWORDS: migrations, Yugoslavia, Palestine, Israel, Jews, Ernest Beschinsky, Ilsa Beschinsky 